\title{
The Clinical Utility of Circulating Microparticles’ Measurement in Heart Failure Patients
}

\section{Berezin $\mathrm{AE}^{\star}$}

Consultant of Therapeutic Unit, Internal Medicine Department, State Medical University of Zaporozhye, Ukraine

\begin{abstract}
Heart failure (HF) continues to have a sufficient impact on morbidity, mortality and disability in developed countries. Growing evidence supports the hypothesis that microparticles (MPs) might contribute to the pathogenesis of the HF development paling a pivotal role in the regulation of the endogenous repair system, thrombosis, coagulation, inflammation, immunity and metabolic memory phenomenon. Therefore, there is a large body of data clarifying the predictive value of MP numerous in circulation among subjects with HF. Although determination of MP signature is better than measurement of single MP circulating level, there is not yet closely confirmation that immune phenotype of cells produced MPs are important for HF prediction and development. The aim of the review: to summarize knowledge regarding the measurement of number of various MPs subsets in HF patients.
\end{abstract}

Keywords: Heart failure; Microparticles; Diagnosis; Stratification; Prediction

\begin{abstract}
Abbreviations: BMI: Body Mass Index; BNP: Brain Natriuretic Peptide; CHF: Chronic Heart Failure; CV: Cardiovascular; EVs: Extracellular Vesicles; HF: Heart Failure; HFpEF: Chronic HF with Preserved Ejection Fraction; HFrEF: Chronic HF with Reduced Ejection Fraction; HSP: Heart Shock Protein; GFR: Glomerular Filtration Rate; hs-CRP: High Sensitive C-Reactive Protein; HDL-C: High-Density Lipoprotein Cholesterol; ICAM: Intracellular Adhesion Molecule; LDL-C: Low-Density Lipoprotein Cholesterol; LVEF: Left Ventricular Ejection Fraction; MPs: Microparticles; MI: Myocardial Infarction; STEMI:ST: Segment Elevation Myocardial Infarction; PGF: Placental Growth Factor; PLGA: Poly Lactic-co-Glycolic Acid; VCAM: Vascular Cell Adhesion Molecule; VEGF: Vascular Endothelial Growth Factor
\end{abstract}

\section{Introduction}

Heart failure (HF) continues to have a sufficient impact on morbidity, mortality and disability in developed countries [1]. However, within last decades the prevalence of HF have been progressively decreased predominantly HF with reduced left ventricular ejection fraction (HFrEF) [2]. In contrast, frequency of novel cases of HF with preserved left ventricular ejection fraction (HFpEF) appears to be raised [3]. These changes in epidemiology of HF depend in particularly on the implementation of contemporary strategy regarding early diagnosis, prevention, treatment of HF [4], as well as resulting in effect of aging, sex, socioeconomic status and co-morbidities [5-8]. Nevertheless, male gender, current smoker status, increased highly sensitive troponin $\mathrm{T}$, and previous myocardial infarction were associated with new onset HFrEF, whereas female gender, history of atrial fibrillation, increased urinary albumin excretion, and cystatin $\mathrm{C}$ were conferred new onset HFpEF [9]. However, higher age, obesity and increased N-terminal pro-B-type natriuretic peptide (NT-proBNP) increased the risk for both HFpEF and HFrEF [9].

Although improving the management of HF remains a priority for health care services, the outcome of HF patients remains poor despite modern pharmacological and none-pharmacological therapies including established devices i.e. cardiac resynchronization therapy devices and implantable defibrillator/cardioverters $[8,10]$. Furthermore, the clinical outcomes of both phenotypes of HF have been occurred similar or at least not sufficiently distinguished [11] that is important challenge for contemporary medical care service.
There is growing awareness of the role of several predictive tools reflecting various pathophysiological stages of cardiac dysfunction development for risk stratification of the patients with both phenotypes of HF. Most studies have described the utility of biological markers in HF for diagnosis, prediction, and even biomarker-guided therapy, but by now natriuretic peptides, soluble ST2, galectin-3, and high sensitive cardiac specific troponins were validated only $[4,12]$. As expected, the routine use of biomarkers on diagnosis of HF might help to stratify the patients at higher risk of death and clinical outcomes. In fact, both 2012 European Society of Cardiology (ESC) Guidelines for the Diagnosis and Treatment of Acute and Chronic Heart Failure and 2013 American College of Cardiology Foundation/American Heart Association (ACCF/AHA) Guideline for the Management of Heart Failure are well accepted by many clinicians regarding diagnosis and prognosis of HFrEF. In contrast, diagnosis and prediction of HFpEF with biomarkers is still challenging for practitioners [13]. However, there was not a large body of evidence regarding perspectives to may provide clinically useful prognostic information both concerning the future risk of HFpEF/HFrEF manifestation in asymptomatic subjects, the risk of fatal events and primary/re-admissions in the hospital in individuals for those have already established symptomatic acute, acutely decompensated/advanced, and chronic stable HF related to ischemic and non-ischemic causes [14]. It is suggested that multi morbidity in HF may limit the diagnostic and predictive utility of biomarkers [15].

There are current available data regarding the role of cardiac remodeling, inflammation, thrombosis, worsening of endothelial integrity and endothelium injuries are common for HF onset and

*Corresponding author: Berezin $\mathrm{AE}$, Professor, $\mathrm{MD}, \mathrm{PhD}$, Consultant of Therapeutic Unit, Internal Medicine Department, State Medical University of Zaporozhye, 26, Mayakovsky av, Zaporozhye, UA-69035, Ukraine, Tel: +380612894585; E-mail: dr_berezin@mail.ru; aeberezin@gmail.com

Received May 13, 2016; Accepted May 26, 2016; Published June 06, 2016

Citation: Berezin AE (2016) The Clinical Utility of Circulating Microparticles Measurement in Heart Failure Patients. J Vasc Med Surg 4: 277. doi: 10.4172/23296925.1000277

Copyright: (c) 2016 Berezin AE. This is an open-access article distributed unde the terms of the Creative Commons Attribution License, which permits unrestricted use, distribution, and reproduction in any medium, provided the original author and source are credited. 
development beyond etiology [16,17]. Moreover, HF may closely associate with release of newly detectable circulating biomarkers currently called microparticles (MPs) $[18,19]$. The aim of the review: to summarize knowledge regarding the role of various MPs in diagnosis and prognosis of HF.

\section{Definition, Classification, Structure and Regulation of Microparticles}

MPs are defined a heterogeneous sub-population of extracellular vesicles (EVs) with diameter average from 100 to1000 nm originated from plasma membranes of mother' cells. EVs are phospholipid-based endogenously produced particles (30-1000 $\mathrm{nm}$ in diameter), which contain cell-specific collections of proteins, glycoproteins, lipids, nucleic acids and other molecules. Abundant cells including cardiomyocites, blood cells, endothelial cells, immune cells, and even tumor cells are capable to secrete MPs of different size and compositions.

Depending on their origin EVs are graduated to follow subsets, i.e. the exosomes (30-100 $\mathrm{nm}$ in diameter), the microvesicles (50-1000 $\mathrm{nm}$ in diameter), ectosomes (100-350 $\mathrm{nm}$ in diameter), small-size MPs ( $<50 \mathrm{~nm}$ in diameter) known as membrane particles and apoptotic bodies (1-5 $\mu \mathrm{m}$ in diameter). The exosomes are formed by inward budding of the endosomal membrane and are released on the exocytosis of multivesicular bodies (MVBs) known as late endosomes, whereas the microvesicles are attributed via budding from plasma membranes [20]. However, the exosomes have been predominantly labeled in the case of immune cells (macrophages, T cells, B cells and dendritic cells) and tumor cells. Unlike the exosomes, the ectosomes are ubiquitous microvesicles assembled at and released from the plasma membrane [21].

MPs are released by cellular vesiculation and fission of the membrane of cells [22]. Under normal physiological condition a phospholipid bilayer of plasma membrane of cells represented phosphatidylserine and phosphatidylethanoalamine in inner leaflets, whereas phosphatidylcholine and sphingomyelin represent in the external leaflets. The asymmetrical distribution of phospholipids in the plasma membrane is supported by activity of three major intracellular ATP-dependent enzyme systems, i.e. flippase, floppase, and scramblase. Because aminophospholipids are negatively charged, but phospholipids exhibit neutral charge, the main role of intracellular enzyme systems is supporting electrochemical gradient. Both flippase and floppase belong to family of ATP-dependent phospholipid translocases.

The flippase translocates phosphatidylserine and phosphatidylethanoalamine from the external leaflets to the inner one. The floppase transports phospholipids in the opposite direction. Finally, scramblase being to $\mathrm{Ca}^{2+}$-dependent enzyme system exhibits unspecifically ability of moving of phospholipids between both leaflets of plasma membrane.

Importantly, disappearing of the asymmetrical phospholipid distribution in the bilayer of the cell membrane is considered a clue for vesiculation and forming of MPs. Indeed, both processes of apoptosis or cell activation are required asymmetry in phospholipid distribution that leads to cytoskeleton modifications, membrane budding and MPs release. The mechanisms of vesiculation affect genome and may mediate by some triggers including inflammation [23], while in some cases there is a spontaneous release of MPs from stable cells or due to injury from necrotic cells or from mechanically damaged cells. Particularly, the MPs are released in both constitutive and controlled manners, regulated by intercellular $\mathrm{Ca}^{2+}$ and Rab-GTP-ases and activation of $\mu$-calpain. $\mu$-Calpain is a $\mathrm{Ca}^{2+}$-dependent cytosolic enzyme belong to protease, which cleaves talin and $\alpha$-actin, leading to decreased binding of integrins to the cytoskeleton and a reduction in cell adhesion and integrity. Finally, interaction of the actin and myosin is a main component for cytoskeleton modification that creates a contractile force and drives the formation of membrane MPs.

Recently MPs are considered a cargo for various molecules. Indeed, MPs carry proteins, RNA, micro-RNA, and DNA fragments from their cells of origin to other parts of the body via blood and other body fluids. Within last decade it has become to know that MPs would act as information transfer for target cells. However, the difference between innate mechanisms affected the release of MPs from stable cells, activated cells or apoptotic cells is yet not fully investigated and requires more studies.

The majority (more than 90\%) of MPs in healthy controls are of platelet origin, whereas less than $10 \%$ originate from granulocytes and less than $5 \%$ from endothelial cells, red blood cells and monocytes [24]. Since all types of particles contain surface proteins derived from their cell of origin (including antigen-presenting cells), while there are additional biomarkers confirming origin of the MPs. The key features of several MP populations are reported in Table 1. Taking into consideration the difference between contents and umber of MPs various origin it has been suggested that signature of MPs might be used as potential biomarker of several disease, i.e. metabolic and $\mathrm{CV}$ disease including HF.

\section{Biological Role and Function of MPs}

Microparticles have great potentiality in material science-based applications [25], while initially they were recognized as cell debris beyond any biological function. Developments of technologies that attenuate recognize, determination, and measurements of MPs obtained from various cells appear to be indispensable tool to clinical medicine [26].

Recent investigations have been shown that MPs as derivate of cellular membrane are discussed powerful paracrine regulators of target cell functions [27-29]. Indeed, MPs possess a wide spectrum of biological effects on intercellular communication by transferring different molecules (autoantigens, cytokines, mRNA, iRNA, hormones, tissue coagulation factors, and surface receptors) able to modulate other cells affected growth of tissue, reparation, vasculogenesis, inflammation, apoptosis, infection, and malignancy. However, MPs are not only cargo for biological active substances. Growing evidence supports the idea that regarding association between immune pattern of MPs originated from different cells (endothelial cells, mononuclears, dendritic cells, platelets) and nature evolution of various diseases including CV diseases, cancer, sepsis, eclampsia, autoimmune and metabolic states, etc. [30-33].

Mononuclear cell-derived MPs are involved in inflammation, blood coagulation, and thrombosis [34,35]. Mononuclears may generate pro-inflammatory MPs upon activation and apoptosis with a calcium-dependent and p38 mitogen-activated protein kinasedependent mechanisms resulting in impact of cytokines, bacterial products, P-selectin, histamine, catecholamines, angiotensin-II, cigarette smoking [36-40]. Furthermore, mononuclear cell-derived MPs may appear spontaneously beyond obvious cause in physiological state $[39,40]$.

Circulating mononuclear cell-derived MP like RBCs-derived MPs may provide an additional pro-coagulant phospholipid surface 
Citation: Berezin AE (2016) The Clinical Utility of Circulating Microparticles' Measurement in Heart Failure Patients. J Vasc Med Surg 4: 277. doi: 10.4172/2329-6925.1000277

Page 3 of 11

\begin{tabular}{|c|c|c|}
\hline Types of MPs & Markers & Detection \\
\hline \multicolumn{3}{|c|}{ Derived from resting or activated cells } \\
\hline Granulocytes & CD24+CD11c- CD66b/CD66acde & \multirow{11}{*}{$\begin{array}{l}\text { Flow cytometry western blotting, mass spectrometry, electron } \\
\text { microscopic technique, SPRi microscopy }\end{array}$} \\
\hline Monocytes & CD14 & \\
\hline Microphages & CD11b+ CD64+/- Ly6Clo & \\
\hline Endothelial cells & CD144, CD62E & \\
\hline T cells & CD4 or CD8 & \\
\hline B cells & CD20 & \\
\hline Dendritic cells & CD1a, CD14, CD141, CD80, CD85, CD86 & \\
\hline ICAM $(+)$ cells & CD54 & \\
\hline VCAM(+)cells & CD106 & \\
\hline Platelets & CD41 and/or CD61 & \\
\hline Erythrocytes & $\begin{array}{l}\text { CD235a, CD44, CD47, CD55, CFSE, annexin V and } \\
\text { anti-glycophorin A }\end{array}$ & \\
\hline Derived from activated or tumor cells & $\begin{array}{l}\text { Annexin V binding, CD63, CD81, CD9, LAMP1 and } \\
\text { TSG101 }\end{array}$ & Flow cytometry, capture based assays \\
\hline Derived from apoptotic cells & Annexin V, DNA content, histones & Flow cytometry \\
\hline
\end{tabular}

Abbreviations: ICAM: Intracellular Adhesion Molecule; VCAM: Vascular Cell Adhesion Molecule; SPRi Microscopy, Nano-particles-surface Plasmon Resonance-based Imaging Microscopy; CFSE: Carboxyfluorescein Diacetate Succinimidyl Ester.

Table 1: Key features of MP populations.

enabling the assembly of the clotting enzymes complexes and thrombin generation [41,42]. It has noted the release or recruitment of pro-coagulant MPs at sites of endothelium injury or worsening of integrity through P-selectin pathway could be enhanced or triggered by tissue factor activity [43]. Converging evidences from experimental or clinical data highlight a role for MP harboring tissue factor in the initiation of disseminated intravascular coagulopathy.

Additionally, their role in the regulation of lipid metabolism through peroxisome proliferator-activated receptor- $\gamma$ (PPAR- $\gamma$ ) is exerted. Moreover, some PPAR- $\gamma$ agonists have been linked to an increased risk of thrombotic diseases [44]. Interestingly, angiotensin II may up-regulate the generation of pro-coagulant MPs by human mononuclear cells that confirms a hypothesis about linking between the renin-angiotensin systems to thrombosis [45]. Therefore, there is evidence that elderly persons compared with young persons may have different patterns of expression of mononuclear cells derived MPs and pro-coagulant activity in stable condition and diseases [46].

In is well known that MPs appear to be found into circulation in response to many situational changes (physiological conditions, stress, laminar shear stress on endothelium) micro-environmental stimulation, coagulation/thrombosis, endotoxinemia, activated cells or those undergoing apoptosis, ischemic injury, hypoxia, and malignancy [47-49]. Optionally, it is well known that several haemodynamic conditions via laminar shear stress may stimulate a secretion of MPs from endothelial cells. There are some controversial in understanding of regulation in MPs' secretion. There are data that confirm a close link between high endothelial shear stress and release of MPs from endothelial cells [50]. In opposite, an inverse association between number of endothelial cell-derived MPs in circulation and shear stress values was found [51]. Authors have suggested that increased release MPs following apoptosis of endothelial cells may be trigger of low laminar stress.

Thus, MPs depending on their origin, structure and inducers secretion might possess both physiological (cell-to-cell cooperation, regulation of endogenous reparation, angiogenesis) and pathological effects (promoting oxidative stress, vascular inflammation, coagulation, neovascularization).

Key mechanisms by which MPs may exert their biological functions on cells are shown Figure 1. Currently the role of MPs in pathogenesis of several diseases is elucidated and the numbers of studies devoted MPs-regulated processes in the CV diseases, rheumatic diseases, infections, are dramatically raised [51-54]. However, MPs play critical roles in almost all physiological events occurring in tissues and organs (Figure 2).

Because MPs formation and shedding involve reconstitution of cell membrane phospholipid structure, which contains pro-coagulant tissue factors, there is suggesting that MPs especially originating from RBCs may act ac inducers and regulators of coagulation. Indeed, erythrocytes actively shed phospholipid-bound MPs [54]. MPs originating from erythrocytes are naturally produced in vivo during normal aging processes or they have associated with a variety of pathophysiological conditions including hematology diseases (hemolysis, sickle cell disease and thalassemia), chronic kidney disease (IgA nephropathy), uremia, stroke, acute infections, sepsis, trauma, thrombosis/embolia, allograft dysfunction [55-60]. Therefore, erythrocytes-derived MPs may secrete ex vivo during cold storage of RBCs [61].

It has been defined that lipopolysaccharides, immune complexes, complement components, abnormal hemoglobin variants might lead to vesiculation, membrane instability, and loss of membrane asymmetry of erythrocytes with exposal of phosphatidylserine $[55,56]$. This potentiates thrombin generation resulting in activation of the coagulation cascade via the tenase and prothrombinase complexes responsible for subclinical phenotypes and increase of the atherothrombotic and CV risk [62]. However, there is serious controversial in understanding an ability of MPs derived from RBS, leukocytes, endothelial cells regulate coagulations cascade through generation of plasmin formation. Endothelial cell-derived and leukocyte-derived MPs provide the real support to plasminogen activator activity, whereas platelets-derived and RBCs-derived MPs do not contribute to the fibrinolytic activity of MPs isolated from peripheral blood [62]. Therefore, circulating erythrocyte-derived MPs exhibits procoagulant properties related to factor XI presentation on their surface [63]. Furthermore, complement activation on the RBCs leads to the shedding of erythrocytes-derivedMPs that may express complement and tissue factor thus promoting inflammation and thrombosis [64]. On the other hand, erythrocytesderived MPs present fibrinolytic activity mainly due to the presence of plasminogen on them [65]. 
Citation: Berezin AE (2016) The Clinical Utility of Circulating Microparticles' Measurement in Heart Failure Patients. J Vasc Med Surg 4: 277. doi: 10.4172/2329-6925.1000277

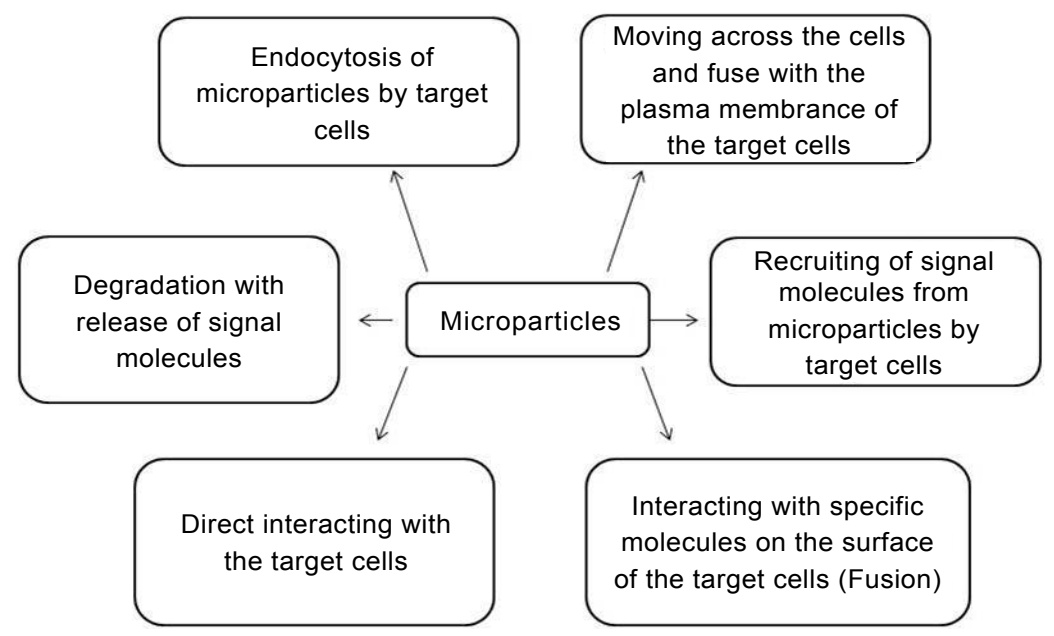

Figure 1: The key mechanisms of MP exertion on target cells.

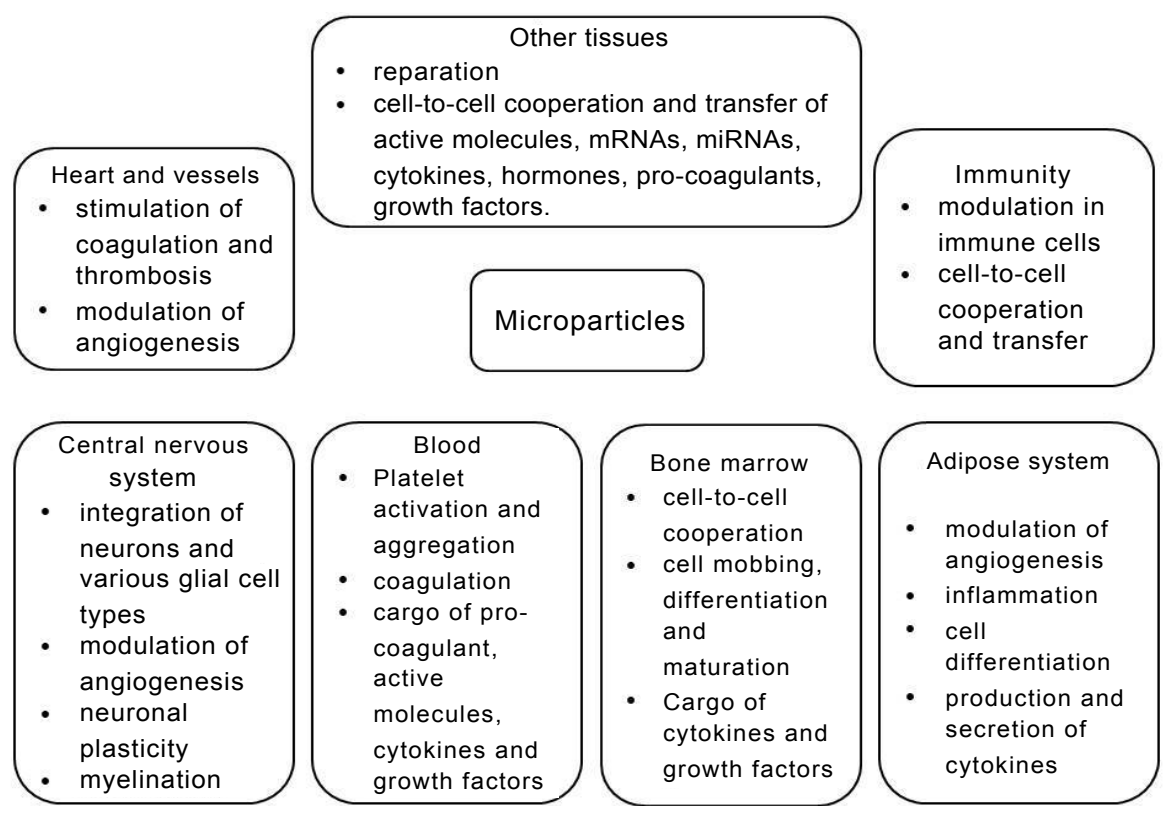

Figure 2: The role of microparticles in physiological events occurring in tissues and organs.

Koshiar RL et al. [66] concluded that the erythrocyte-derived MP surface is suitable for the anticoagulant reactions of the protein $\mathrm{C}$ system, which is important to balance the initiation and propagation of coagulation in vivo. Therefore, extracellular protein-bound RNAs (such as microRNA) derived from RBCs-MPs may play a role in transfusion-related immunomodulation [54].

The microvesicular bodies released from antigen presenting cells, tumor cells, and macrophages. The primary role of many microvesicular bodies is as an intermediate in a general degradative lysosomal pathway. These can transfer miRNA, proteins and lipids between cells and they could be involved in transcription, immune modulation and angiogenesis [67].

Platelet MPs are resulting in activation, stress, or apoptosis of platelets like several types of nucleus cells. Platelet MPs a phospholipidbased structure and express in abundant functional receptors from platelet membranes, the pro-coagulant phosphatidylserine and probably complement. The main biological role of platelet-derived MP is regulating in hemostasis, thrombosis, cancer, and inflammation, however, they may act as promoters of tissue regeneration [68-71].

There is a large body of evidences regarding the role of plateletderived MPs a cargo tool of bioactive molecules (i.e. growth factors, other signaling molecules and micro-RNA), but they display mediating of the cellular environment with the vasculature and have an important vector function for the intercellular exchange of biological information [72].

Endothelial cells-derived MPs are released by inducer like angiotensin II, lipopolysaccharide, and hydrogen peroxide leading to the worsening of endothelial integrity, endothelial dysfunction, development and progression of microvascular inflammation [47]. All these processes relate to atherosclerosis, thrombosis, HF progression 
and lead to major CV events. However, there are multiple physiological pathways for endothelial cells-derived MPs generation like NADPH oxidase derived endothelial ROS formation, Rho kinase pathway, and mitogen-activated protein kinases.

Increasing evidence suggests that endothelial cells-derived MPs play an important role in the pathogenesis of CV disease, acting as a marker of damage, either exacerbating disease progression or triggering a repair response. Indeed, endothelial cells-derived MPs depending on their origin (apoptotic cells or shedding from activated endothelial cell) might have a different structure and produce controversial effects. MPs derived from apoptotic endothelial cells are capable of transferring biological information (regulating peptides, active molecules, hormones) or even genetic materials (micro-RNA, mRNA, and DNA), as well as proteins, lipid components, from one cell to another without direct cell-to-cell contact to maintain cell homeostasis [73]. Apoptotic MPs secreted by endothelial cells may be not only immune mediators, generating powerful signaling by the simultaneous receptor interaction, but they are discussed a marker of endothelial cell injury, coagulation/ thrombosis and vascular aging [74]. Contrary, EMPs derived from activated endothelial cells did not contain nuclear components and they may exhibit angiogenic properties and contribute to tissue protection [75-77]. It has been suggested that an ability of various cells to secrete MPs may depend on epigenetic modifications and that this cell phenotype alteration by cell-derived vesicles presents a new aspect for consideration of HF development [78]. In this context, it has been suggested that numbers and phenotype of endothelial cells-derived MPs have the potential biomarkers of $\mathrm{CV}$ disease.

\section{Microparticles in Cardiovascular Disease}

Numbers of circulating MPs originated from several cells are changed in patients with known CV disease including HF. However, focus of investigations is found in the field of MPs derived from blood cells and endothelial cells $[79,80]$. Their increased level in plasma is regarded as a biomarker of alteration in vascular function, coagulation, neovascularization resulting in shear stress, inflammation, direct cell injury, endothelium cell activation or apoptosis, and probably activated vascular reparation $[18,19,23,47]$. Recent studies have been shown that elevated level of blood cells-derived MPs was higher in the patients with CV disease compared with healthy individuals [79-84]. However, the role of MPs originated from blood cells and endothelial cells in CV diseases sufficiently distinguishes.

\section{Erythrocytes-derived MPs}

Although RBC-derived MPs are emerging entities found to play direct roles in coagulation, inflammation, and immunomodulation via interactions with other plasma cells, their role in the pathogenesis of $\mathrm{CV}$ disease including HF is not yet completed. There is evidence that erythrocyte-derived MPs are released from evolving growing thrombi into the distal perfusing blood in patients with acute myocardial infarction [85]. Therefore, elevated level of MPS originated from RBCs can be measured in peripheral blood. Investigators have concluded MPs derived from RBCs may constitute a novel systemic biomarker of ongoing thrombosis [85]. Probably, changes in the pattern of RBCsderived MP signature may associate with the developing of thromboocclusive vascular process in the coronary arteries of acute myocardial infarction patients [86].

Sansone R et al. [87] have been investigated the pattern of circulating MPs originated from wide spectrum of cells, i.e. erythrocytes, leukocytes, endothelial cells, platelets, in end-stage HF subjects with implanting left ventricular assist devices. Authors reported that increased red and white cell MPs, as well as and endothelial cellderived MPs and platelet-derived MPs were observed in subjects implantation of left ventricular assist devices. However, the mechanical support leads to significant improvements in microvascular perfusion, hemodynamics and decrease the circulating level of MPs irrespective their origin. No any advantages in measurement of RBCs-derived MPs in end-stage HF subjects with implanting left ventricular assist devices were found. Empana JP et al. [88] reported that number of erythrocyte (CD235a+)-derived MPs in patients with sudden cardiac death due to acute coronary occlusion was not differ subjects with stable coronary artery disease.

However, the abundant data indicate the causality role of elevated RBCs-derived MPs in C events resulting in hemoglobinopathies, blood transfer, and autoimmunity. Although the data confirming the role of RBCs-derived MPs in CV disease are very limited, quantification of MPs originated from RBCs may provide utility for identifying patients who are at increased risk of both thrombotic or CV events and would help to monitor response to therapy.

\section{Leukocyte-derived MPs}

The leukocyte-derived MPs were found in higher concentrations in the patients with acute coronary syndrome and STEMI, asymptomatic atherosclerosis, obesity, diabetes, HF [89-91]. The monocyte CD14(+) MPs were implicated in the modulation of the post-acute coronary syndrome reparative response to injury [90]. Morel O. et al. (2009) [91] have been investigated the levels and cellular origins of MPs within the occluded coronary artery of patients with STEMI treated by primary angioplasty. It has reported that the levels of leukocyte-derived CD11a(+) MPs, endothelial cell-derived CD105(+) MPs, and tissue factor (TF)-bearing MPs were significantly higher within the occluded coronary artery than in peripheral blood samples received from the patients with acute myocardial infarction [91]. Authors found that restoration of the epicardial blood flow led to a significant reduction of pro-coagulant CD11a(+) and CD105(+) MPs ( $<<0.05)$. Likewise, all these findings might clarify that the elevation of pro-coagulant MPs within the occluded coronary artery of patients with STEMI suggests their pathophysiological role in coronary atherothrombosis.

Petrini S et al. (2016) [92] suggested that leptin playing a pivotal role in the pathogenesis of metabolically active obese, insulin resistance and diabetes mellitus may induce the shedding of pro-coagulant, tissue factor bearing MPs by peripheral blood mononuclear cells. Authors reported that leptin through increased intracellular calcium mobilization induced generation of pro-coagulant mononuclear cellsderived MPs linking obesity and atherothrombotic risk.

Overall, the leukocyte-derived MPs are considered a marker of cell injury, coagulation and inflammation. Whether MPs originate from stable and activated leukocytes are similar in their ability to damage of several tissue via direct and indirect mechanisms affecting interaction with other cells is not yet clear.

\section{Platelet-derived MPs}

Platelet-derived MPs are defined in higher concentration in patients with acute coronary syndrome, myocardial infarction, heparin-induced thrombocytopenia, thrombotic thrombocytopenic purpura, hemolytic uremic syndrome, and other thrombotic disorders. Interestingly, the level of platelet-derived MPs was not increased in obesity, diabetes mellitus, insulin resistance, antiphospholipid syndrome, infection disease or sepsis [93]. Probably, this evidence 
might relate to the mechanisms regarding release of MPs from platelets. It has suggested that in various cases circulating platelets are likely to adhere to leukocytes or endothelial cells at the activation site and that the circulating platelet-derived MPs are likely to be a residue of activated platelets [94].

Although the importance of platelet-derived MPs in the pathogenesis of CV diseases is still debated [93-96], there are data regarding directly effect of platelet-derived MPs on formation of foam cells in atherosclerotic plaque [97]. Therefore, increased level of circulating platelet-derived MPs was found in older age individuals without $\mathrm{CV}$ disease, as well as in the younger individuals with high $\mathrm{CV}$ risk due to subclinical atherosclerosis [96] and patients with known CV diseases [97]. However, the fractions of platelet-derived MPs expressed P-selectin or CD63 were higher in the patients with peripheral arterial disease and ST-segment elevation myocardial infarction [97] that confirmed the role of activated platelets-derived MPs in the pathogenesis of thrombus formation and platelet aggregations [98]. Moreover, beyond biomarkers of cell activation, platelets-derived MPs have functional effects on the development of damaged vessel wall-induced arterial thrombi and blood thrombogenicity on areas of arterial damage contributing to atherothrombotic events [99]. Michelsen et al. [100] have found the increased level of platelet-derived MPs in survivors of acute myocardial infarction correlated well with thrombosis and soluble CD40 ligand. Authors concluded that the independent association between large platelet-derived MPs and thrombin generation supports the concept that formation of plateletderived MPs is important for increased coagulation activation in acute myocardial infarction patients.

Interestingly, the platelet-derived MPs are discusses not only factor directly mediating endothelial dysfunction and atherosclerosis, but they contribute to vascular reparation following vascular injury acting via correspondence with endothelial progenitor cells [93]. Moreover, endothelial progenitor cells may consolidates their interaction with platelets under dynamic flow conditions through secretion of plateletderived MPs [97,99-102]. By now, it is known that platelet-derived MPs may interact with angiogenic early outgrowth cells in the context of vascular injury and modulate their regenerative potential [103]. BajKrzyworzeka M et al. [104] reported that platelet-derived MPs may modulate biological functions of hematopoietic cells and that they play an important but as yet not fully understood role in intercellular cross-talk in hematopoiesis and regeneration. Ohtsuka $M$ et al. [105] have shown that platelet-derived MPs were reported to augment the re-endothelialization capacity of circulating angiogenic cells. All these support the hypothesis regarding angiopoetic capability of plateletsderived MPs [106].

Although the innate mechanisms regarding regulation of plateletderived MPs secretion and impact on target cells are not fully elucidated and required more investigations, increased content of platelet-derived MPs, even in normal blood conditions, may enhance vascular damage and thrombus formation. Finally, it is suggested that platelet-derived MPs may be considered a potential biological marker for vascular dysfunction and CV disease severity and may be implicated in the pathogenesis of coagulation abnormalities encountered in patients with known CV diseases and CV events.

\section{Endothelial cells-derived MPs}

The number of endothelial cells-derived MPs is widely considered a marker of endothelial dysfunction in CV diseases. Recent clinical studies have shown that numerous of CD31+/annexin V+ endothelial cells-derived MPs strongly correlate with endothelial function and CV outcomes in stable CAD patients $[107,108]$. Moreover, Huang et al. [109] reported that increased circulating CD31+/annexin V+ EMPs and decreased circulating EPCs predict target organ damage in hypertensive patients. The higher concentrations of endothelial-derived MPs have been found in patients with acute coronary syndrome, sudden cardiac death due to acute coronary occlusion and stable angina [89]. Moreover, number of endothelial-derived MP (CD42-CD31+) closely and inversaly relate to indexes of microvascular obstruction in acute myocardial infarction patients [110]. Yet, it has reported that patients with metabolic (obesity, metabolic syndrome and T2DM) and CV (stable coronary artery disease, asymptomatic atherosclerosis, acute coronary syndrome, myocardial infarction, hypertension, HF) may have impaired ratio between number of apoptotic endothelial cells-derived MPs and MPs derived from activated endothelial cells $[101,111]$. This imbalance was predominantly associated with increased number of MPs derived from apoptotic endothelial cells and labeled as $\mathrm{CD} 31+$ /annexin $\mathrm{V}+$, whereas number of activated endothelial cellsderived MPs with the phenotype CD62E+ did not change or appeared to be tendency to decrease [112]. Indeed, elevated CD31+/annexin V+ to $\mathrm{CD} 62 \mathrm{E}+$ ratio was fond as indicator of impaired immune phenotype of endothelial cells-derived MPs, which allows determining pattern of MPs in CV disease patients [112]. This phenomenon was recognized as "impaired phenotype" of endothelial cells-derived MPs and it has related to cellular injury, inflammation, coagulation/thrombosis leading to vascular dysfunction and contributing to CV risk $[111,113]$. Finally, "impaired phenotype" of endothelial cells-derived MPs appearing as epigenetic reprogramming of mother' cells play a pivotal role in the development of CV complications [113-115].

It has been suggested that not only endothelial cells that epigenetically transformed into "functionally incompetence cells" might produce wide spectrum of MPs, which may directly worse target cells. However, in HF patients the role of the endothelial cells-derived MPs is more profoundly investigated than MPs originated from other types of cells.

Although there was a skepticism regarding origin of imbalance in several poles of endothelial cells-derived MP in patients with obesity and diabetes, it has supposed that inflammatory cytokine and probably lipid abnormalities may consider a possible cause of predominantly immune phenotype of endothelial cells-derived MPs [116]. The skepticism is based on findings regarding a pivotal role of increased glucose level, inflammatory cytokine and lipid abnormalities in the development of impaired phenotypes seen in CV disease patients. Indeed, glucose toxicity and lipid toxicity are recognized as main contributors of metabolic memory affected epigenetic reprogramming of various types of progenitor cells.

By now, endothelial progenitor cells have been found as component of endogenous repair system, which mediates tissue repair including microvasculature and microvasculature damages [117]. There are current available data regarding that the endothelial cellsderived MPs interact with or enter different target cells from other tissues, altering their phenotype toward that of the cell releasing the vesicles $[118,119]$. Cells may be changed by direct interactions with microvesicles, transfer of cell surface receptors or directly epigenetic reprogramming via transcriptional regulators derived with circulating MPs [120,121]. Thus, endothelial cells-derived MPs are essential for cross-communication between cells and they may underlie the phenomenon of tissue reparation.

Additionally, the circulating endothelial cells-derived MPs are 
involved in the cell-to-cell cooperation supporting mobbing and differentiation of the progenitor cells. Moreover, the dysfunction of progenitor cells has been recently described as an essential factor contributed to microvascular and microvascular complications in diabetes, metabolic syndrome and obesity. In this context, "impaired phenotype" of endothelial cells-derived MPs is a link between CV risk factors and epigenetic reprogrammed progenitor cells $[118,122]$. Indeed, pattern of endothelial cells-derived MPs in HF patients has associated with well-recognized metabolic risk factors (i.g. insulin resistance, inflammation, thyroid dysfunction) beyond metabolic syndrome or T2DM [123-125] and probably "impaired phenotype" of endothelial cells-derived MPs could be predictor of CV events and HF development in general population and in patients at higher risk of $\mathrm{CV}$ diseases.

Obviously HF patients might have different endothelial cellsderived MP' patterns contributing to the development of CV complications depending on the type of reprogramming of mother' cells. Whether abnormal pattern of endothelial cells-derived MPs would be appeared prior to metabolic states manifestation or, in contrast, several metabolic states (i.e. diabetes, metabolic syndrome, obesity) are able to induce an imbalance between various endothelial cells-derived MPs via epigenetic reprogramming mechanisms affected matter' cells secreting MPs is not still clear and requires more investigations.

\section{Diagnostic and Predictive Value of Circulating Microparticles in Heart Failure}

Signature of circulating MPs reflecting various stage of pathogenesis of HF could be a biomarker of HF development and progression, as well as a predictor of different phenotypes of HF, clinical outcomes and survival rate [126]. Bank IE et al. [127] believe that both MPscounts and MPs-content are associated with CV disease. Probably the identification of plasma MPs is a novel source of blood-based biomarkers with the potential to improve diagnosis and prognosis of $\mathrm{CV}$ events including HF.

Several MPs are detecting in this context, whereas endothelial cellsderived MPs appear to be more promised. The higher level of CD62+ MPs secreted from activated endothelial cells in the healthy subjects versus HF patients was related to rather endothelial dysfunction than endothelial cell injury [128]. We found that pattern of circulating endothelial cells-derived MPs in chronic HF patients has related to neurohumoral and inflammatory activation [129]. Moreover, we suggested that the patter recently described as "impaired phenotype" might have a predictive value in patients with HF irrespective HF phenotypes [130]. This phenomenon has defined as elevated levels of MPs derived from apoptotic endothelial cells and decreased level of CD62E + MPs secreted by activated endothelial cells. We have been widely investigated this phenomenon in both HF phenotypes and in patients without known CV diseases and HF. Interestingly, that the results of our investigations have not exhibited any significance changes in CV comorbidities between HFrEF and HFpEF patients, probably due to similar molecular mechanisms that might lead to endothelial cell activation [131]. However, it has suggested that lack of sufficiently difference between co-morbidities' presentation among HFrEF and HFpEF groups might express similar finding [132]. Interestingly, because of the number of existing CV risk factors is variable between HF patients, simple signature of MPs do not adequately describe vascular disease risk in all clinical conditions and, as such, the $\mathrm{CV}$ risk remains [121]. Indeed, elevated levels of circulating CD62e(+) endothelial cellderived MPs but not leukocytes-derived MPs in patients with cardiac dysfunction due to pulmonary hypertension prior to treatment are associated with adverse clinical events [132].

The concept of "impaired" phenotype as imbalance between factors originated endothelium with innate angiogenic and/or injury capacities directly contributed in the endothelial dysfunction and require further investigation because the molecular mechanism of their release into circulation still requires more elucidations [133]. Indeed, number of apoptotic MPs derived from endothelial cells alone and adjusted to number of mononuclear progenitor cells exhibited a higher predictive value for HF clinical outcomes than traditional biomarkers including NT-proBNP and galectin-3 [134]. Moreover, CD31+/annexin V+ endothelial cells-derived MPs to CD14+CD309+ cells ratio added to NT-proBNP, clinical data, and cardiovascular risk factors has exhibited the best discriminate value and higher reliability to predict HFpEF compared with NT-proBNP and clinical data/CV risk factors alone [131]. There were prompts to create novel predictive score based on measurement of circulating biomarkers including endothelial-derived MPs [135,136]. Thus, "impaired immune phenotype" of circulating endothelial-derived MPs became a novel biomarker of HF development and progression $[137,138]$.

\section{Conclusions}

The interest of the scientific community in the role of MPs in HF development and progression has expanded rapidly over the last decades. MPs coordinate wide spectrum biological processes, i.e. angiogenesis, neovascularization, cell growth/differentiation, proliferation, coagulation, and they are involved in the epigenetic regulation of post-processing that is essential for phenotype modification, tissue repair, cell death, malignancy, and immunity. Numbers of circulating MPs derived from blood cells and endothelial cell, were found a marker of endothelial dysfunction and predictor of CV complications in dysmetabolic subjects including obesity and diabetes, as well as in individuals at higher risk of CV diseases and subjects with known CV disease including HF. Finally, using of MPs appears to be promised as diagnostic and predictive biomarker.

\section{Acknowledgments}

This research received no specific grant from any funding agency in the public commercial, or not-for-profit sectors.

\section{References}

1. van Riet EE, Hoes AW, Wagenaar KP, Limburg A, Landman MA, et al. (2016) Epidemiology of heart failure: the prevalence of heart failure and ventricular dysfunction in older adults over time. A systematic review. Eur J Heart Fail 18: $242-252$.

2. Jorge AL, Rosa ML, Martins WA, Correia DM, Fernandes LC, et al. (2016) The Prevalence of Stages of Heart Failure in Primary Care: A Population-Based Study. J Card Fail 22: 153-157.

3. Banerjee $P(2016)$ Heart failure with preserved ejection fraction: A clinical crisis. Int J Cardiol 204: 198-199.

4. Yancy CW, Jessup M, Bozkurt B, Butler J, Casey DE, et al. (2013) ACCF/AHA guideline for the management of heart failure: $A$ report of the American College of Cardiology Foundation/American Heart Association Task Force on Practice Guidelines. J Am Coll Cardiol 62: e147-e239.

5. Buja A, Solinas G, Visca M, Federico B, Gini R, et al. (2016) Prevalence of Heart Failure and Adherence to Process Indicators: Which Socio-Demographic Determinants are Involved? Int J Environ Res Public Health. 13:238.

6. Kosiborod M, Lichtman JH, Heidenreich PA, Normand SL, Wang Y, et al (2006) National trends in outcomes among elderly patients with heart failure. Am J Med 119: 616.

7. Frankenstein L, Clark AL, Ribeiro JP (2012) Influence of sex on treatment and outcome in chronic heart failure. Cardiovasc Ther 30: 182-192. 
Citation: Berezin AE (2016) The Clinical Utility of Circulating Microparticles' Measurement in Heart Failure Patients. J Vasc Med Surg 4: 277. doi: 10.4172/2329-6925.1000277

Page 8 of 11

8. Rathore SS, Masoudi FA, Wang Y, Curtis JP, Foody JM, et al. (2006) Socioeconomic status, treatment, and outcomes among elderly patients hospitalized with heart failure: Findings from the National Heart Failure Project. Am Heart J 152:371-378.

9. Brouwers FP, de Boer RA, van der Harst P, Voors AA, Gansevoort RT, et al (2013) Incidence and epidemiology of new onset heart failure with preserved vs. reduced ejection fraction in a community-based cohort: 11-year follow-up of PREVEND. Eur Heart J 34: 1424-1431.

10. Hawkins NM, Virani SA, Sperrin M, Buchan IE, McMurray JJ, et al. (2015) Predicting heart failure decompensation using cardiac implantable electronic devices: a review of practices and challenges. Eur J Heart Fail .

11. McMurray JJ (2015) Improving outcomes in heart failure: a personal perspectiveae. Eur Heart J 36: 3467-3470.

12. McMurray JJ, Adamopoulos S, Anker SD, Auricchio A, Bohm M, et al. (2012) ESC guidelines for the diagnosis and treatment of acute and chronic hear failure 2012: The Task Force for the Diagnosis and Treatment of Acute and Chronic Heart Failure 2012 of the European Society of Cardiology. Eur J Heart Fail 14: 803-869.

13. Butler J, Fonarow GC, Zile MR, Lam CS, Roessig L, et al. (2014) Developing therapies for heart failure with preserved ejection fraction: current state and future directions. JACC Heart Fail 2: 97-112.

14. D’Elia E, Vaduganathan M, Gori M, Gavazzi A, Butler J, et al. (2015) Role of biomarkers in cardiac structure phenotyping in heart failure with preserved ejection fraction: critical appraisal and practical use. Eur J Heart Fail 17: 1231 1239.

15. Chamberlain AM, St Sauver JL, Gerber Y, Manemann SM, Boyd CM, et al (2015) Multimorbidity in heart failure: a community perspective. Am J Med 128: $38-45$.

16. Paulus WJ, Tschöpe C (2013) A novel paradigm for heart failure with preserved ejection fraction: comorbidities drive myocardial dysfunction and remodeling through coronary microvascular endothelial inflammation. J Am Coll Cardio 62: $263-271$

17. Fujisue K, Sugiyama S, Matsuzawa Y, Akiyama E, Sugamura K, et al. (2015) Prognostic Significance of Peripheral Microvascular Endothelial Dysfunction in Heart Failure With Reduced Left Ventricular Ejection Fraction. Circ J 79: 26232631.

18. Dignat-George F, Boulanger CM (2011) The many faces of endothelia microparticles. Arterioscler Thromb Vasc Biol 31: 27-33.

19. Burger D, Touyz RM (2012) Cellular biomarkers of endothelial health microparticles, endothelial progenitor cells, and circulating endothelial cells. $J$ Am Soc Hypertens 6: 85-99.

20. Berezin A (2015) Endothelial Derived Micro Particles: Biomarkers for Heart Failure Diagnosis and Management. J Clin Trial Cardiol 2: 1-3.

21. Cocucci E, Meldolesi J (2015) Ectosomes and exosomes: shedding the confusion between extracellular vesicles. Trends Cell Biol 25: 364-372.

22. Colombo M, Raposo G, Théry C (2014) Biogenesis, secretion, and intercellula interactions of exosomes and other extracellular vesicles. Annu Rev Cell Dev Biol 30: 255-289.

23. Piccin A, Murphy WG, Smith OP (2007) Circulating microparticles: pathophysiology and clinical implications. Blood Rev 21: 157-171.

24. Tesselaar ME, Romijn FP, Van DL, Prins FA, Bertina RM, et al. (2007) Microparticle-associated tissue factor activity: a link between cancer and thrombosis? J Thromb Haemost 5:520-527.

25. Sarkar S, Dasgupta AK (2015) Microparticle of drug and nanoparticle: a biosynthetic route. Pharmacol Res Perspect 3: e00188.

26. Gu Z, Jing C, Ying YL, He P, Long YT (2015) In situ high throughput scattering light analysis of single plasmonic nanoparticles in living cells. Theranostics 5 : 188-195.

27. Gong J, Jaiswal R, Dalla P, Luk F, Bebawy M (2015) Microparticles in cancer: A review of recent developments and the potential for clinical application. Semin Cell Dev Biol 40: 35-40.

28. Das S, Halushka MK (2015) Extracellular vesicle microRNA transfer in cardiovascular disease. Cardiovasc Pathol 24: 199-206.

29. Berezin A, Zulli A, Kerrigan S, Petrovic D, Kruzliak P (2015) Predictive role of circulating endothelial-derived microparticles in cardiovascular diseases. Clin Biochem 48: 562-568.

30. Jadli A, Sharma N, Damania K, Satoskar P, Bansal V, et al. (2015) Promising prognostic markers of preeclampsia: new avenues in waiting. Thromb Res 136 189-195.

31. Greening DW, Gopal SK, Mathias RA, Liu L, Sheng J, et al. (2015) Emerging roles of exosomes during epithelial-mesenchymal transition and cancer progression. Semin Cell Dev Biol 40: 60-71.

32. Martinez MC, Andriantsitohaina R (2011) Microparticles in angiogenesis: therapeutic potential. Circ Res 109: 110-119.

33. Souza AC, Yuen PS, Star RA (2015) Microparticles: markers and mediators of sepsis-induced microvascular dysfunction, immunosuppression, and AKI. Kidney Int 87: 1100-1108.

34. Neri T, Pergoli L, Petrini S, Gravendonk L, Balia C, et al. (2016) Particulate matter induces prothrombotic microparticle shedding by human mononuclear and endothelial cells. Toxicol In Vitro. 32: 333-338

35. Aleman MM, Gardiner C, Harrison P, Wolberg AS (2011) Differential contributions of monocyte- and platelet-derived microparticles towards thrombin generation and fibrin formation and stability. J Thromb Haemost 9: 2251-2261.

36. Cordazzo C, Petrini S, Neri T, Lombardi S, Carmazzi Y, et al. (2014) Rapid shedding of proinflammatory microparticles by human mononuclear cells exposed to cigarette smoke is dependent on Ca2+ mobilization. Inflamm Res 63: $539-547$.

37. Li M, Yu D, Williams KJ, Liu ML (2010) Tobacco smoke induces the generation of procoagulant microvesicles from human monocytes/macrophages. Arterioscler Thromb Vasc Biol 30: 1818-1824.

38. Novelli F, Neri T, Tavanti L, Armani C, Noce C, et al. (2014) Procoagulant, tissue factor-bearing microparticles in bronchoalveolar lavage of interstitial lung disease patients: an observational study. PLoS One 9: e95013.

39. Vatsyayan R, Kothari H, Pendurthi UR, Rao LV (2013) 4-Hydroxy-2-nonenal enhances tissue factor activity in human monocytic cells via p38 mitogenactivated protein kinase activation-dependent phosphatidylserine exposure. Arterioscler Thromb Vasc Biol 33: 1601-1611.

40. Satta N, Toti F, Feugeas O, Bohbot A, Dachary-Prigent J, et al. (1994) Monocyte vesiculation is a possible mechanism for dissemination of membraneassociated procoagulant activities and adhesion molecules after stimulation by lipopolysaccharide. J Immunol 153: 3245-3255.

41. Morel N, Morel O, Delabranche X, Jesel L, Sztark F, et al. (2006) [Microparticles during sepsis and trauma. A link between inflammation and thrombotic processes]. Ann Fr Anesth Reanim 25: 955-966.

42. Chung SM, Bae ON, Lim KM, Noh JY, Lee MY, et al. (2007) Lysophosphatidic acid induces thrombogenic activity through phosphatidylserine exposure and procoagulant microvesicle generation in human erythrocytes. Arterioscler Thromb Vasc Biol 27: 414-421.

43. Kawata J, Aoki M, Ishimaru Y, Ono T, Sagara K, et al. (2015) Mechanism of tissue factor production by monocytes stimulated with neutrophil elastase. Blood Cells Mol Dis 54: 206-209.

44. Neri T, Cordazzo C, Carmazzi Y, Petrini S, Balia C, et al. (2012) Effects of peroxisome proliferator-activated receptor-? agonists on the generation of microparticles by monocytes/macrophages. Cardiovasc Res 94: 537-544.

45. Cordazzo C, Neri T, Petrini S, Lombardi S, Balia C, et al. (2013) Angiotensin II induces the generation of procoagulant microparticles by human mononuclear cells via an angiotensin type 2 receptor-mediated pathway. Thromb Res 131 e168-174

46. Forest A, Pautas E, Ray P, Bonnet D, Verny M, et al. (2010) Circulating microparticles and procoagulant activity in elderly patients. J Gerontol A Bio Sci Med Sci 65: 414-420.

47. Lynch SF, Ludlam CA (2007) Plasma microparticles and vascular disorders. $\mathrm{Br}$ J Haematol 137: 36-48.

48. Sabatier F, Camoin-Jau L, Anfosso F, Sampol J, Dignat-George F (2009) Circulating endothelial cells, microparticles and progenitors: key players towards the definition of vascular competence. J Cell Mol Med 13: 454-471.

49. Burnier L, Fontana P, Kwak BR, Angelillo-Scherrer A (2009) Cell-derived microparticles in haemostasis and vascular medicine. Thromb Haemost $101:$ 439-451. 
Citation: Berezin AE (2016) The Clinical Utility of Circulating Microparticles' Measurement in Heart Failure Patients. J Vasc Med Surg 4: 277. doi: 10.4172/2329-6925.1000277

Page 9 of 11

50. Brodsky SV, Zhang F, Nasjletti A, Goligorsky MS (2004) Endothelium-derived microparticles impair endothelial function in vitro. Am J Physiol Heart Circ Physiol 286: H1910-1915.

51. Boulanger CM, Amabile N, Guérin AP, Pannier B, Leroyer AS, et al. (2007) In vivo shear stress determines circulating levels of endothelial microparticles in end-stage renal disease. Hypertension 49: 902-908.

52. Buzas El, György B, Nagy G, Falus A, Gay S (2014) Emerging role of extracellular vesicles in inflammatory diseases. Nat Rev Rheumatol 10: 356 364

53. Vader P, Breakefield XO, Wood MJ (2014) Extracellular vesicles: emerging targets for cancer therapy. Trends Mol Med 20: 385-393.

54. Muszynski JA, Bale J, Nateri J (2015) Supernatants from stored red blood cell (RBC) units, but not RBC-derived microvesicles, suppress monocyte function in vitro. Transfusion 55: 1937-1945.

55. Cognasse F, Hamzeh-Cognasse H, Laradi S, Chou ML, Seghatchian J, et al. (2015) The role of microparticles in inflammation and transfusion: A concise review. Transfus Apher Sci 53: 159-167.

56. Chakrabarti A, Halder S, Karmakar S (2016) Erythrocyte and platelet proteomics in hematological disorders. Proteomics Clin Appl 10: 403-414.

57. Piccin A, Murphy C (2015) Circulating microparticles, protein C, free protein $S$ and endothelial vascular markers in children with sickle cell anaemia. $J$ Extracell Vesicles 4: 28414

58. Gao C, Ji S, Dong W, Qi Y, Song W, et al. (2015) Indolic uremic solutes enhance procoagulant activity of red blood cells through phosphatidylserine exposure and microparticle release. Toxins (Basel) 7: 4390-4403.

59. Zhang Y, Meng H, Ma R, He Z, Wu X, et al. (2016) Circulating Microparticles, Blood Cells and Endothelium Induce Procoagulant Activity in Sepsis Through Phosphatidylserine Exposure. Shock 45: 299-307.

60. Harms A, Fuehner T, Warnecke G, Haverich A, Gottlieb J, et al. (2015) Epithelial and Erythrocyte Microvesicles From Bronchoalveolar Lavage Fluid Are Elevated and Associated With Outcome in Chronic Lung Allograft Dysfunction. Transplantation 99: 2394-2400.

61. Prudent M, Crettaz D, Delobel J, Seghatchian J, Tissot JD, et al. (2015) Differences between calcium-stimulated and storage-induced erythrocytederived microvesicles. Transfus Apher Sci 53: 153-158.

62. Lacroix R, Plawinski L, Robert S, Doeuvre L, Sabatier F, et al. (2012) Leukocyteand endothelial-derived microparticles: a circulating source for fibrinolysis. Haematologica 97: 1864-1872.

63. van Beers EJ, Schaap MC, Berckmans RJ, Nieuwland R, Sturk A, et al. (2009) CURAMA study group. Circulating erythrocyte-derived microparticles are associated with coagulation activation in sickle cell disease. Haematologica 94:1513-1519

64. Karpman D, Stahl AL, Arvidsson I, Johansson K, Loos S, et al. (2015) Complement Interactions with Blood Cells, Endothelial Cells and Microvesicles in Thrombotic and Inflammatory Conditions. Adv Exp Med Biol 865: 19-42.

65. Levin G, Sukhareva E, Lavrentieva A (2016) Impact of microparticles derived from erythrocytes on fibrinolysis. J Thromb Thrombolysis 41: 452-458.

66. Koshiar RL, Somajo S, Norström E, Dahlbäck B (2014) Erythrocyte-derived microparticles supporting activated protein C-mediated regulation of blood coagulation. PLoS One 9: e104200.

67. Carmeliet P, Jain RK (2011) Molecular mechanisms and clinical applications of angiogenesis. Nature 473: 298-307.

68. Goubran HA, Burnouf T, Stakiw J, Seghatchian J (2015) Platelet microparticle: a sensitive physiological "fine tuning" balancing factor in health and disease. Transfus Apher Sci 52: 12-18.

69. Sinauridze E, Kireev DA, Popenko NY, Pichugin AV, Panteleev MA, et al. (2007) Platelet microparticle membranes have 50- to 100 -fold higher specific procoagulant activity than activated platelets. Thromb Haemost 97: 425-434.

70. Nomura S (2009) Dynamic role of microparticles in type 2 diabetes mellitus. Curr Diabetes Rev 5: 245-251.

71. Varon D, Shai E (2009) Role of platelet-derived microparticles in angiogenesis and tumor progression. Discov Med 8: 237-241.

72. Nomura S (2001) Function and clinical significance of platelet-derived microparticles. Int J Hematol 74: 397-404.
73. Puddu P, Puddu GM, Cravero E, Muscari S, Muscari A (2010) The involvement of circulating microparticles in inflammation, coagulation and cardiovascular diseases. Can J Cardiol 26:140-145.

74. Jimenez JJ, Jy W, Mauro LM, Soderland C, Horstman LL, et al. (2003) Endothelial cells release phenotypically and quantitatively distinct microparticles in activation and apoptosis. Thromb Res 109: 175-180.

75. Arteaga RB, Chirinos JA, Soriano AO, Jy W, Horstman L, et al. (2006) Endothelial microparticles and platelet and leukocyte activation in patients with the metabolic syndrome. Am J Cardiol 98: 70-74.

76. Quesenberry PJ, Aliotta JM (2010) Cellular phenotype switching and microvesicles. Adv Drug Deliv Rev 62: 1141-1148.

77. Berezin AE (2016) Metabolic memory phenomenon in diabetes mellitus: achieving and perspectives. Diabetes \& Metabolic Syndrome: Clinical Research \& Reviews.

78. Inal JM, Kosgodage U, Azam S, Stratton D, Antwi-Baffour S, et al. (2013) Blood/ plasma secretome and microvesicles. Biochim Biophys Acta 1834: 2317-2325.

79. Berezin AE (2015) Impaired Pattern of Endothelial Derived Microparticles in Heart Failure Patients. J Mol Genet Med 9:1.

80. Berezin AE, Kremzer AA, Martovitskaya Yu V, Samura TA, Berezina TA (2015) The Association of Subclinical Hypothyroidism and Pattern of Circulating Endothelial-Derived Microparticles Among Chronic Heart Failure Patients. Res Cardiovasc Med 4: e29094.

81. Paudel KR, Panth N, Kim DW (2016) Circulating Endothelial Microparticles: A Key Hallmark of Atherosclerosis Progression. Scientifica (Cairo) 2016 8514056.

82. Horn P, Baars T, Kahlert P, Heiss C, Westenfeld R, et al. (2015) Release of Intracoronary Microparticles during Stent Implantation into Stable Atherosclerotic Lesions under Protection with an Aspiration Device. PLoS One 10: e0124904

83. Morel O, Luca F, Grunebaum L, Jesel L, Meyer N, et al. (2011) Short-term very low-calorie diet in obese females improves the haemostatic balance through the reduction of leptin levels, $\mathrm{PAl}-1$ concentrations and a diminished release of platelet and leukocyte-derived microparticles. Int J Obes (Lond) 35: 1479-1486

84. Liu Y, He Z, Zhang Y, Dong Z, Bi Y, et al. (2016) Dissimilarity of increased phosphatidylserine-positive microparticles and associated coagulation activation in acute coronary syndromes. Coron Artery Dis

85. Suades R, Padró T, Vilahur G, Martin-Yuste V, Sabaté M, et al. (2015) Growing thrombi release increased levels of $\mathrm{CD} 235 \mathrm{a}(+)$ microparticles and decreased levels of activated platelet-derived microparticles. Validation in ST-elevation myocardial infarction patients. J Thromb Haemost 13: 1776-1786.

86. Suades R, Padró T, Crespo J, Ramaiola I, Martin-Yuste V, et al. (2016) Circulating microparticle signature in coronary and peripheral blood of ST elevation myocardial infarction patients in relation to pain-to- $\mathrm{PCl}$ elapsed time. Int J Cardiol 202: 378-387.

87. Sansone R, Stanske B, Keymel S, Schuler D, Horn P, et al. (2015) Macrovascular and microvascular function after implantation of left ventricular assist devices in end-stage heart failure: Role of microparticles. J Heart Lung Transplant 34:921-932.

88. Empana JP, Boulanger CM, Tafflet M, Renard JM, Leroyer AS, et al. (2015) Microparticles and sudden cardiac death due to coronary occlusion. The TIDE (Thrombus and Inflammation in sudden DEath) study. Eur Heart J Acute Cardiovasc Care 4: 28-36.

89. Wang ZT, Wang Z, Hu YW (2016) Possible roles of platelet-derived microparticles in atherosclerosis. Atherosclerosis 248: 10-16.

90. Montoro-Garcia S, Shantsila E, Tapp LD, López-Cuenca A, Romero Al, et al. (2013) Small-size circulating microparticles in acute coronary syndromes: relevance to fibrinolytic status, reparative markers and outcomes. Atherosclerosis 227: $313-322$

91. Morel O, Pereira B, Averous G, Faure A, Jesel L, et al. (2009) Increased levels of procoagulant tissue factor-bearing microparticles within the occluded coronary artery of patients with ST-segment elevation myocardial infarction: role of endothelial damage and leukocyte activation. Atherosclerosis 204: 636641.

92. Petrini S, Neri T, Lombardi S, Cordazzo C, Balia C, et al. (2016) Leptin induces the generation of procoagulant, tissue factor bearing microparticles by human peripheral blood mononuclear cells. Biochim Biophys Acta 1860: 1354-1361. 
Citation: Berezin AE (2016) The Clinical Utility of Circulating Microparticles' Measurement in Heart Failure Patients. J Vasc Med Surg 4: 277. doi: 10.4172/2329-6925.1000277

Page 10 of 11

93. Burnouf T, Goubran HA, Chou ML, Devos D, Radosevic M (2014) Platelet microparticles: detection and assessment of their paradoxical functional roles in disease and regenerative medicine. Blood Rev 28: 155-166.

94. Osumi K, Ozeki Y, Saito S, Nagamura Y, Ito H (2001) Development and assessment of enzyme immunoassay for platelet-derived microparticles. Thromb Haemost 85: 326-330.

95. Tan KT, Lip GY (2005) The potential role of platelet microparticles in atherosclerosis. Thromb Haemost 94: 488-492.

96. Suades R, Padró T, Alonso R, Mata P, Badimon L (2015) High levels of TSP1+/CD142+ platelet-derived microparticles characterise young patients with high cardiovascular risk and subclinical atherosclerosis. Thromb Haemost 114:1310-1321.

97. van der Zee PM, Biró E, Ko Y, de Winter RJ, Hack CE, et al. (2006) P-selectinand CD63-exposing platelet microparticles reflect platelet activation in peripheral arterial disease and myocardial infarction. Clin Chem 52: 657-664.

98. Min PK, Kim JY, Chung KH, Lee BK, Cho M, et al. (2013) Local increase in microparticles from the aspirate of culprit coronary arteries in patients with STsegment elevation myocardial infarction. Atherosclerosis 227: 323-328.

99. Suades R, Padró T, Vilahur G, Badimon L (2012) Circulating and plateletderived microparticles in human blood enhance thrombosis on atherosclerotic plaques. Thromb Haemost 108: 1208-1219.

100. Michelsen AE, Brodin E, Brosstad F, Hansen JB (2008) Increased level of platelet microparticles in survivors of myocardial infarction. Scand J Clin Lab Invest 68: 386-392.

101. Alexandru N, Andrei E, Dragan E, Georgescu A (2015) Interaction of platelets with endothelial progenitor cells in the experimental atherosclerosis: Role of transplanted endothelial progenitor cells and platelet microparticles. Biol Cell 107: $189-204$

102. Berezin AE (2015) Are Endothelial Cell-Derived Microparticles Predictive Biomarkers in Cardiovascular Diseases? Atherosclerosis: open Access 1: e101-e103.

103. Mause SF, Ritzel E, Liehn EA, Hristov M, Bidzhekov K, et al. (2010) Platelet microparticles enhance the vasoregenerative potential of angiogenic early outgrowth cells after vascular injury. Circulation 122: 495-506.

104.Baj-Krzyworzeka M, Majka M, Pratico D, Ratajczak J, Vilaire G, et al. (2002) Platelet-derived microparticles stimulate proliferation, survival, adhesion, and chemotaxis of hematopoietic cells. Exp Hematol 30: 450-459.

105. Ohtsuka M, Sasaki K, Ueno T, Seki R, Nakayoshi T, et al. (2013) Plateletderived microparticles augment the adhesion and neovascularization capacities of circulating angiogenic cells obtained from atherosclerotic patients. Atherosclerosis 227: 275-282.

106. Chen BA, Zhong YJ, Huang CY, Li CP, Shi GY, et al. (2007) Effects of plateletderived membrane microparticles on angiogenesis in chick chorioallantoic membranes. Zhongguo Shi Yan Xue Ye Xue Za Zhi 15: 1070-1073.

107. Sinning JM, Losch J, Walenta K, Böhm M, Nickenig G, et al. (2011) Circulating CD31+/Annexin V+ microparticles correlate with cardiovascular outcomes. Eur Heart J 32: 2034-2041.

108. Werner N, Wassmann S, Ahlers P, Kosiol S, Nickenig G (2006) Circulating $\mathrm{CD} 31+$ /annexin $\mathrm{V}+$ apoptotic microparticles correlate with coronary endothelial function in patients with coronary artery disease. Arterioscler Thromb Vasc Biol 26: 112-116.

109. Huang PH, Huang SS, Chen YH, Lin CP, Chiang KH, et al. (2010) Increased circulating CD31+/annexin V+ apoptotic microparticles and decreased circulating endothelial progenitor cell levels in hypertensive patients with microalbuminuria. J Hypertens 28: 1655-1665.

110. Porto I, Biasucci LM, De Maria GL, Leone AM, Niccoli G, et al. (2012) Intracoronary microparticles and microvascular obstruction in patients with ST elevation myocardial infarction undergoing primary percutaneous intervention. Eur Heart J 33: 2928-2938.

111. Berezin AE, Kremzer AA, Samura TA, Berezina TA, Kruzliak P (2015) Impaired immune phenotype of circulating endothelial-derived microparticles in patients with metabolic syndrome and diabetes mellitus. J Endocrinol Invest 38: 865-874.

112. Chironi GN, Boulanger CM, Simon A, Dignat-George F, Freyssinet JM, et al. (2009) Endothelial microparticles in diseases. Cell Tissue Res 335: 143-151.
113. Shantsila E (2009) Endothelial microparticles: a universal marker of vascular health? J Hum Hypertens 23: 359-361.

114. Camussi G, Deregibus MC, Bruno S, Grange C, Fonsato V, et al. (2011) Exosome/microvesicle-mediated epigenetic reprogramming of cells. Am J Cancer Res 1: 98-110.

115. Théry C, Ostrowski M, Segura E (2009) Membrane vesicles as conveyors of immune responses. Nat Rev Immunol 9: 581-593.

116. Wang Y, Chen LM, Liu ML (2014) Microvesicles and diabetic complications-novel mediators, potential biomarkers and therapeutic targets. Acta Pharmaco Sin 35: 433-443.

117. Mause SF, Weber C (2010) Microparticles: protagonists of a nove communication network for intercellular information exchange. Circ Res 107: 1047-1057.

118. Montoro-García S, Shantsila E, Marín F, Blann A, Lip GY (2011) Circulating microparticles: new insights into the biochemical basis of microparticle release and activity. Basic Res Cardiol 106: 911-923.

119. Berezin AE (2015) Berezin AE. Circulating Endothelial-Derived Apoptotic Microparticles as Novel Perspective Biomarker for Diabetes. Diabetes Res Treat Open Access 1: 117-120.

120. Berezin AE, Kremzer AA, Martovitskaya YV, Berezina TA, Gromenko EA (2016) Pattern of endothelial progenitor cells and apoptotic endothelial cellderived microparticles in chronic heart failure patients with preserved and reduced left ventricular ejection fraction. EBioMedicine 4: 86-94.

121. Berezin AE, Kremzer AA, SamuraTA, Berezina TA, Kruzliak P (2015) Impaired immune phenotype of circulating endothelial-derived microparticles in patients with metabolic syndrome and diabetes mellitus. J Endocrin Investigation 38 : 865-74.

122. Berezin A, Kremzer A, Cammarota G, Zulli A, Petrovic D, Martell-Claros N et al. (2015) Circulating endothelial-derived apoptotic microparticles and insulin resistance in non-diabetic patients with chronic heart failure. Clinical Chemistry and Laboratory Medicine 54: 1259-67.

123. Berezin AE, Kremzer AA, Martovitskaya YuV, Berezina TA, Samura TA (2015) Pattern of circulating endothelial-derived microparticles among chronic heart failure patients with dysmetabolic comorbidities: The impact of subclinical hypothyroidism. Diabetes \& Metabolic Syndrome: Clinical Research \& Reviews 10: 29-36.

124. Berezin AE, Kremzer AA, Samura TA, Berezina TA, Kruzliak P (2015) Impaired immune phenotype of circulating endothelial-derived microparticles in patients with metabolic syndrome and diabetes mellitus. J Endocrinol Invest 38: 865-874.

125. Berezin A (2015) Small-size endothelial-derived microparticles as nove predictive biomarkers in cardiovascular diseases. Angiology 3: 145-148

126. Dignat-George F, Boulanger CM (2011) The many faces of endothelial microparticles. Arterioscler Thromb Vasc Biol 31: 27-33.

127. Bank IE, Timmers (2015) The diagnostic and prognostic potential of plasma extracellular vesicles for cardiovascular disease. Expert Rev Mol Diagn 15 $1577-1588$

128. Burger D, Touyz RM (2012) Cellular biomarkers of endothelial health: microparticles, endothelial progenitor cells and circulating endothelial cells. J Am Soc Hypertens 6: 85-99

129. Berezin AE, Kremzer AA, Berezina TA, Martovitskaya YuV (2015) Pattern of circulating microparticles in chronic heart failure patients with metabolic syndrome: Relevance to neurohumoral and inflammatory activation. BBA Clinical 4: 69-75

130. Berezin AE, Kremzer AA, Martovitskaya YV, Samura TA, Berezina TA (2014) The predictive role of circulating microparticles in patients with chronic heart failure. BBA Clin 3: 18-24

131.Sen S, McDonald SP, Coates PT, Bonder CS (2011) Endothelial progenitor cells: novel biomarker and promising cell therapy for cardiovascular disease. Clin Sci (Lond) 120: 263-283.

132. Amabile N, Heiss C, Chang V, Angeli FS, Damon L, Rame EJ, et al. (2009) Increased $\mathrm{CD} 62 \mathrm{e}(+)$ endothelial microparticle levels predict poor outcome in pulmonary hypertension patients. J Heart Lung Transplant 28: 1081-6.

133. Shantsila E, Lip GY (2016) Endothelial Progenitors and Blood Microparticles: 
Citation: Berezin AE (2016) The Clinical Utility of Circulating Microparticles' Measurement in Heart Failure Patients. J Vasc Med Surg 4: 277. doi: 10.4172/2329-6925.1000277

Are They Relevant to Heart Failure With Preserved Ejection Fraction? EBioMedicine 4:5-6

134. Berezin AE, Kremzer AA, Samura TA, Martovitskaya YV, Malinovskiy YV Oleshko SV, Berezina TA (2015) Predictive value of apoptotic microparticles to mononuclear progenitor cells ratio in advanced chronic heart failure patients. J Cardiol 65: 403-11.

135. Berezin AE (2015) Predicting Heart Failure Phenotypes using Cardiac Biomarkers: Hype and Hope. J Dis Markers 2: 1035-1041.
136. Berezin A, Kremzer A, Martovitskaya Y, Samura T, Berezina T (2016) The utility of biomarker risk prediction score in patients with chronic heart failure. Clinical Hypertension 22: 3

137. Berezin A (2015) Impaired Phenotype of Circulating Endothelial-Derived Microparticles: Novel Marker of Cardiovascular Risk. Journal of Cardiology and Therapy 2: 273-278.

138. Berezin AE (2016) Prognostication in different heart failure phenotypes: the role of circulating biomarkers. J Circulating Biomarkers 5:01 